\title{
The Brief Study on AHF at Government Hospital Madhya Pradesh Chhatarpur District; Treatment Outcomes among Patients
}

\author{
Ayush Kumar ${ }^{1 *}$, Sabitha Mary Kurian ${ }^{3}$, Nikita $^{4}$, Raheem Sultana $^{5}$, Y Umama ${ }^{5}$, khan MG ${ }^{2}$, \\ Priyanka Priya ${ }^{2}$ \\ ${ }^{I}$ Department of Pharmacy Practice, MMDU University, India. \\ ${ }^{2}$ Department of Pharmacy, Truba Institute of Pharmacy, India. \\ ${ }^{3}$ Department of Pharmacy Practice, National college of pharmacy, India. \\ ${ }^{4}$ Department of Pharmacy, School of Pharmaceutical, India. \\ ${ }^{5}$ Department of Pharmacy, MRM college of Pharmacy, India.
}

*Corresponding Author: Ayush kumar, Department of Pharmacy Practice, MMDU University, India, E-mail: ayush99kr@gmail.com

\begin{abstract}
Background: Acute Heart failure is very serious condition it required hospital and emergency ward. The aim of this critical Review to evaluate treatment and outcomes and predict a poor treatment outcome in acute heart failure patients at City Chhatarpur Madhya Pradesh.
\end{abstract}

Methods: A randomized prospective study is designed on the basis of data were collection by using questionnaire as a tool. Outcomes variables were assessed at the time patient discharge from the Chhatarpur Hospital. Multivariate and Bivariate used as tool logistic analysis were used to determine factors that show in Hospital mortality. $P$ Value $<0.05$ was significant statistically.

Results: Out of the 200 patients, the median age of patients with acute heart failure 40 years $(I Q R=23$ to $50)$ and median hospital stay was 4.0 days $(I Q R=5.0$ to 7.0). The leading precipitating factor and underlying disease at the time of admission were pneumonia (33.5\%) and chronic rheumatic heart disease (55.5\%), respectively. The in hospital mortality was found to be $24.2 \%$. Smoking (adjusted odds ratio (AOR) = 5.7, $p=0.009)$, diabetes mellitus $(A O R=10.2, p=0.008)$, pulmonary hypertension $(A O R=4.3, p=$ 0.027), and the presence of adverse drug events $(A O R=4.2, p=0.009)$ were predictors of in-hospital mortality.

Conclusion: High in-hospital mortality was observed among acute heart failure patients admitted to a Government Chhatarpur Hospital. Smoking, diabetes mellitus, pulmonary and the presence of adverse drug events were predictors of in-hospital mortality.

Abbreviations: AHF: Acute heart failure, PDT: Patient Drug Therapy

Keywords: Acute heart failure, In-hospital mortality, Predictor of mortality, Chhatarpur Pictorial Abstract:
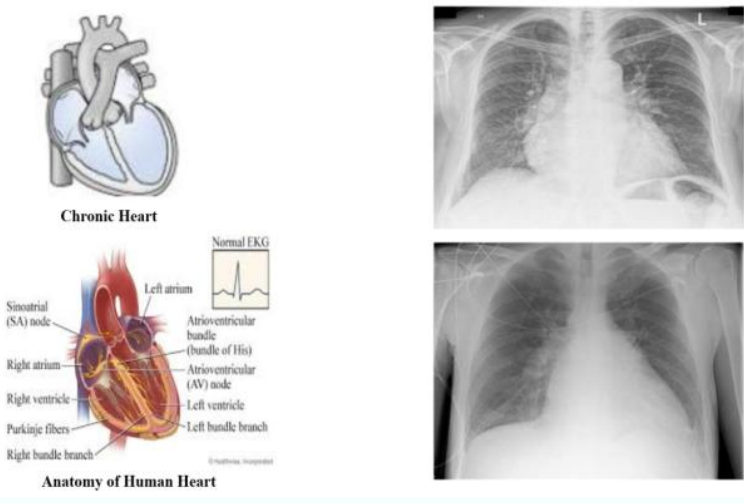


\section{INTRODUCTION}

Acute heart failure (AHF) is a rapid onset of new or worsening of signs and symptoms of heart failure (HF) that is associated with elevated plasma levels of natriuretic peptides. AHF syndromes manifest as new on set 'de novo' or recurrence of acute decompensate heart failure (ADHF) requiring emergency treatment and hospitalization. The incidences of AHF vary in the different part of the world. Its increasing incidence is due to an increasing aging, population, complications arising from cardiovascular diseases like acute coronary syndrome (ACS) and increasing prevalence of lifestyle- related risk factors. AHF patients who attended at hospitals in Africa are young and have severe symptoms due to late presentation. Thus, we should address the young people who are affected by the burden of an acute attack of HF. These younger age group had a significant impact on the economy of the society Adherence to medication predicts health outcomes. Failure to adhere to HF medication was associated with poor treatment outcomes. Patients should receive appropriate therapy as early as possible to achieve good treatment outcomes. Evaluating reasons for hospitalization in AHF is important to give due attention to precipitating factors. The study conducted by Blecker Set.al has shown hospitalized AHF patients didn't receive appropriate therapy besides worsening, AHF was common in hospitalized patients and it was associated with higher mortality rates.

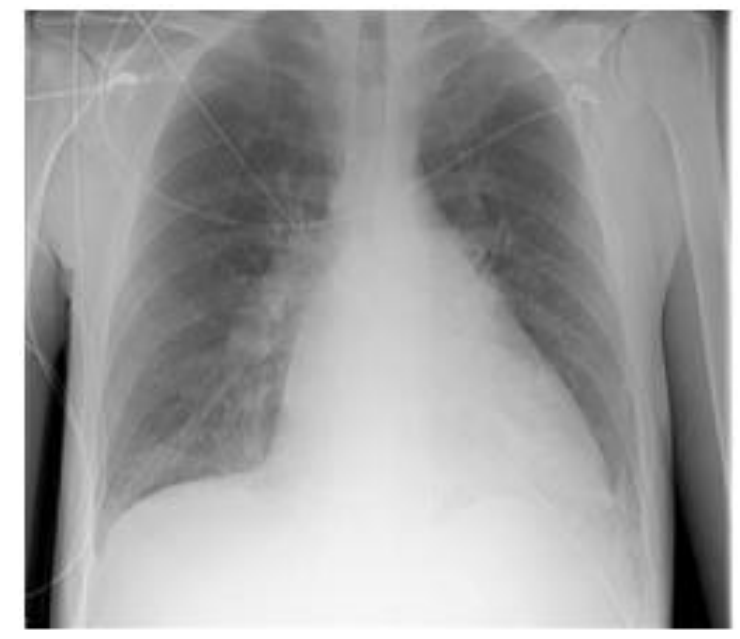

Figure1: Acute heart failure $(A H F)$

Limited studies and literatures are available in India and other developing countries that describe the clinical characteristics, management, and treatment outcome of AHF patients. Therefore, the present study could provide valuable insights to the patient's treatment outcome and predictors of in- hospital mortality among patients hospitalized with AHF in Chhatarpur Madhya Pradesh India.

\section{Methods}

Study design and setting a hospital-based prospective observational study design was used. The study was conducted from April 20 to August 12, 2019, through a structured data abstraction tool. This study was conducted at Chhatarpur Government Hospital, Madhya Pradesh India. It was multispecialty Hospital in whole district. It have 800 beds and serves about 520,000 to 122450 approximately patients in year in our patients and in patients respectively the emergency Department provides the service to about 43,000 patients in year on average 88 patients per day approximately. All patients admitted to the hospital with diagnosis of Acute Heart failure during the Study period were recruited

\subsection{Data Collection}

The data abstraction tool included sociodemographic characteristics, clinical features, laboratory data, precipitating factors, underlying diseases, co-morbidity, imaging studies, treatments given and hospital stay. The treatment outcome was assessed at the time of discharge from the hospital. Ethical clearance was obtained from the Ethical Review Committee of School of Pharmacy, NTR Pharmacy College (Ref. no ERB/MP/20/09/ 2019). Permission was also obtained from the Department of Internal Medicine, School of Medicine, College of Health Sciences, Chiara University. Informed oral consent was obtained from patients and for those whose age was $<18$ years consent as well as assent was obtained from guardians.

\subsection{Data Analysis}

Findings were presented as mean \pm (SD) for normal distributed, otherwise median (interquartile range) for non-normal distributed variables. Categorical variables were reported as percentages and frequency Tables. A chi-square test was used for categorical variables. Bivariate and multivariate logistic regression was used to analyze factors that predict poor treatment outcomes, and variables whose p-values $<0.2$ in the univariate analysis were included in the multivariate model. The level of significance was chosen at $p$-value $\leq 0.05$ and results were 
The Brief Study on AHF at Government Hospital Madhya Pradesh Chhatarpur District; Treatment Outcomes among Patient

reported as 95\% confidence intervals. For all statistical analysis Statistical Package for Social Sciences (SPSS version 20) was used.

\subsection{Data Quality Assurance}

One day training was given for data collectors on the importance, objectives, and method of data collection. There was on-going supervision by the principal investigator. A pre-test was done on 20 consecutive patients to assure clarity, avoidance of ambiguity, comprehensiveness and content uniformity.

\subsection{Operational Definitions}

Acute heart failure: sign and symptoms of newonset of $\mathrm{HF}$ and/or decompensation or worsening of chronic stable HF; Adverse drug events: - any injury occurring at the time of involved PDT [Patient Drug Therapy] outcomes in form unsuitable and from appropriate care ; suboptimal care vice versa .

\subsection{Guidelines on the Basis of Evidence}

Trending Approaches of recurring health management problems that aimed at low

Table: Socio-demographic characteristics of acute failure patient admitted to Government specialized Hospital, Chhatarpur between April 20 to August 12, 2017 (n=200)

\begin{tabular}{|l|c|c|}
\hline \multirow{4}{*}{ Variable } & Description & Frequency (\%) \\
\hline Residence & Urban & $120(71.0)$ \\
\cline { 2 - 3 } & Rural & $49(29.0)$ \\
\cline { 2 - 3 } & No formal education & $30(17.8)$ \\
\cline { 2 - 3 } & Primary school 71 & $71(42.0)$ \\
\cline { 2 - 3 } & Secondary school & $30(17.8)$ \\
\hline \multirow{4}{*}{ Marital status } & Higher education & $38(22.5)$ \\
\cline { 2 - 3 } & Married & $104(61.5)$ \\
\cline { 2 - 3 } & Single & $54(32.0)$ \\
\cline { 2 - 3 } & Divorced & $7(4.2)$ \\
\hline Gender & Widowed & $4(2.4)$ \\
\cline { 2 - 3 } & Female & $92(54.4)$ \\
\hline Smoking & Male & $77(45.6)$ \\
\hline Alcohol intake & Yes & No \\
\hline \multirow{3}{*}{ Alcohol intake } & No & $15(8.9)$ \\
\cline { 2 - 3 } & Yes & No \\
\hline Gender & No & $16(9.5)$ \\
\cline { 2 - 3 } & Yes & $153(90.5)(4.2)$ \\
\hline Smoking & No & $4(2.4)$ \\
\cline { 2 - 3 } & Widowed & $77(45.6)$ \\
\cline { 2 - 3 } & Female & $9(5.3)$ \\
\hline
\end{tabular}

\section{LIMITATIONS}

The present study has the following limitations. This Critical Review Designed and Study is carried in one center with small sample size respectively. In addition, measurements on biomarkers and laboratory values like BNP,
Practice variability to improving health outcomes.

\subsection{Smoker}

Those who are current smokers and had a history of smoking in the last 2 month only; in appropriate dose: - defined according to Indian Society of Cardiology of Acute Heart failure in the first 72 hours as a reference

\section{RESULTS}

Socio-demographic characteristics from a total of 200 AHF patients admitted to the emergency and medical wards of Chhatarpur Government Specialized Hospital between April 20 to August 12, 2019; 20 patients declined to participate and a total of 200 patients who were diagnosed with AHF were included in the study. Of these, $120(80.0 \%)$ patients are urban residents; $104(40.5 \%)$ were married; and 92 $(54.4 \%)$ of the patients were females. of the 200 patients, nine $(6.3 \%)$ were smokers and $19(7.5 \%)$ of the patients were readmitted during the study period (Table 1). and uric acid were not available in this study that could be used significantly to predict the outcome of Acute Heart failure Besides measurement on cardiac troponin, creatine kinase-MB and BUN were not obtained fully. 


\section{CONCLUSION}

High in-hospital mortality rate (22.2\%) was observed among acute heart failure patients admitted to a Government Hospital in Chhatarpur. Chronic RHD and pneumonia were the leading underlying disease and precipitating factors found in patients admitted with AHF, respectively. Smoking, diabetes mellitus, pulmonary hypertension and the presence of adverse drug events were predictors of poor treatment outcomes. Due attention should be given to co-morbid diseases while patients presented with AHF syndromes. Clinicians should also pay more attention to the management of adverse drug events.

\section{ACKNOWLEDGEMENT}

First of all I would like to Thank Ms. U Yezdani Ma'am (Department of Clinical and Pharmacy Practice) Intern Thambey Hospital Hyderabad, India. I also thankful to $\mathrm{Md} \mathrm{G}$ khan sir [My Mentor] for proper guidance and encouragement time to time. I Ayush kumar also thank to all co author's who worked with me in this manuscript.

\section{REFERENCES}

[1] Mebazaa A, Yilmaz MB, Levy P, Ponikowski $\mathrm{P}$, Peacock WF, Laribi S, Ristic AD, Lambrinou E, Masip J, Riley JP. Recommendations on pre-hospital \& early hospital management of acute heart failure: a consensus paper from the heart failure Association of the European Society of cardiology, the European Society of Emergency Medicine and the Society of Academic Emergency Medicine. Eur J Heart Fail. 2015; 17(6):544-58.

[2] Ponikowski P, Voors AA, Anker SD, Bueno H, Cleland JG, Coats AJ, Falk V,GonzálezJuanatey JR, Harjola V-P, Jankowska EA. 2016 ESC guidelines for the diagnosis and treatment of acute and chronic heart failure: the taskforce for the diagnosis and treatment of acute and chronic heart failure of the European Society of Cardiology (ESC) developed with the special contribution of the heart failure association (HFA) of the ESC. Eur Heart J.2016; 37(27): 2129-200.

[3] Gheorghiade M, Pang PS. Acute heart failure syndromes. J Am Coll Cardiol.2009; 53(7): $557-73$.

[4] Roger VL, Go AS, Lloyd-Jones DM, Adams RJ, Berry JD, Brown TM, Carnethon MR, Dai S, De Simone G, Ford ES. Heart disease and strokestatistics-2011 update a report from the
American Heart Association. Circulation. 2011; 123(4):e18-e209.

[5] Damasceno A, Mayosi BM, Sani M, Ogah OS, Mondo C, Ojji D, DzudieA, Kouam CK, Suliman A, Schrueder N. The causes, treatment, and outcome of acute heart failure in 1006 Africans from 9 countries: results of the sub-Saharan Africa survey of heart failure. Arch Intern Med. 2012; 172(18):1386-94.

[6] Ogah OS, Stewart S, Falase AO, Akinyemi JO, Adegbite GD, Alabi AA, Ajani AA, Adesina JO, Durodola A, Sliwa K. Contemporary profile of acute heart failure in southern Nigeria: data from the Abeokuta heart failure clinical registry. JACC Heart Fail. 2014; 2(3): 250-9.

[7] Wu JR, De Walt DA, Baker DW, Schillinger D, Ruo B, Bibbins-Domingo K,MacabascoO'Connell A, Holmes GM, Broucksou KA, Erman B. A Single-Item Self-Report Medication Adherence Question Predicts Hospitalization and Death in Patients with Heart Failure. J Clin Nurs. 2014; 23:2554.

[8] Tsuyuki RT, McKelvie RS, Arnold JO, et al. Acute precipitants of congestive heart failure exacerbations. Arch Intern Med. 2001; 161(19): 2337-42.

[9] Blecker S, Agarwal SK, Chang PP, Rosamond WD, Casey DE, Kucharska-Newton A, Radford MJ, Coresh J, Katz S. Quality of care for heart failure patients hospitalized for any cause. J Am Coll Cardiol. 2014; 63(2):123-30.

[10] DeVore AD, Hammill BG, Sharma PP, Qualls LG, Mentz RJ, Johnson KW, Fonarow GC, Curtis LH, Hernandez AF. In-hospital worsening heart failure and associations with mortality, readmission, and healthcare utilization. J Am Heart Assoc. 2014; 3(4):e001 088.

[11] 11.Mohammad Gayoor Khan ,Umama Yezdani, Shivam Choudghal, Sana Rahman, Mayur Sadar, Ayush Kumar et.al. A Brief Study on Motor Neuron Disease; and its Treatment Includes Drug Delivery System; Future Aspects on Neurological Science" IOSR Journal of Pharmacy and Biological Sciences (IOSRJPBS) 14.4 (2019): 52-56.DOI:10.9790/30081404015256

[12] Umama Yezdani,Mohammad Gayoor khan, ZubiaZainab, Mayur sadar,Shivam Choudghal, Damini Mishra, Hari Baskar. The Current Scenario of Pharmaceutical Research; 3d Tissue Engineering Considered as Eminent Technique. ARC Journal of Public Health and Community Medicine. 2019; 4(2):16-22.

[13] Gayoor Khan, Umama Yezdani, Rohit Verma, Raqshan Jabeen, Pradeep Sintha. Detection of Phlebovirus by using qualitative Real time (RT) - PCR and application of silver nanoparticles to 
control it. World J Pharm Pharm Sci.2018; 7(11):936-52.

[14] Mohd.Gayoor Khan. The Novel Drug Delivery System. World J Pharm Pharm Sci. 2017; 6(7):477-487.

[15] Unama Yezdani, Mohd. Gayoor Khan, Fazal Khan, Arvind Verma, Nilesh Kushwah, Rohit Verma. The Drug Targeting in Alzheimer's or Applications \& its Hazards. World J Pharm Sci.2017; 7(11):1532-1549.

[16] Dr.H. S Chandel, Sharad P. Panday, Arvind Dangi, Ashish chaurasia, Mohd. Gayoor khan et al. Development of Targeted Drug delivery. International Journal of research methodology Ijrm. Human. 2017 Vol. 1 (2): 30-34.

[17] Kushwah Nilesh, Yezdani Umama, Mohammad Gayoor khan, Manish kushwah, Kumar Ayush. The Fundamental of Novel Drug Delivery System; Methodology, Role of Nanotechnology; Nanoparticles in Pharmaceutical Research. International Journal of Emerging Technologies and Innovative Research (www.jetir.org), ISSN: 2349-5162, Vol.6, Issue 6, page no.140-146, June-2019. DOI: http:// doi. one/10.1729/Journal.21510

[18] Mohd. Gayoor Khan, Nilesh Kushwaha, Fazal Khan, Vipul Patel. Microencapsulation. International Journal of research methodology Ijrm. Human. 2017 Vol. 1 (2):35-42.

[19] Sai Kiran NA, Vaishya S, Kale SS, Sharma BS, Mahapatra AK. Surgical results in patients with tuberculosis of the spine and severe lowerextremity motor deficits: a retrospective study of 48 patients. J Neurosurg Spine. 2007; 6:320326. [PubMed] [Google Scholar]
[20] Rezai AR, Lee M, Cooper PR, Errico TJ, Koslow M. Modern management of spinal tuberculosis. Neurosurgery. 1995; 36:87-97. [PubMed] [Google Scholar]

[21] Turgut M. Spinal tuberculosis (Pott's disease): its clinical presentation, surgical management, and outcome. A survey study on 694 patients. Neurosurgeons Rev. 2001; 24:8-13. [PubMed] [Google Scholar]

[22] Barnes PF, Bloch AB, Davidson PT, Snider DE., Jr Tuberculosis in patients with human immunodeficiency virus infection. $\mathrm{N}$ Engl J Med. 1991; 324:1644-1650. [PubMed] [Google Scholar]

[23] Pertuiset E, Beaudreuil J, Liote F, et al. Spinal tuberculosis in adults, A study of 103 cases in a developed country, 1980-1994. Medicine (Baltimore) 1999; 78:309-320. [PubMed] [Google Scholar]

[24] Umama Yezdani Mohammad Gayoor khan, Manish kushwah, Kumar Ayush, Nilesh, Kushwah. The Fundamental of Novel Drug Delivery System; Methodology, Role of Nanotechnology; Nanoparticles in Pharmaceutical Research. International Journal of Emerging Technologies and Innovative Research.6; (6):140-146. https://scholar. google.com/scholar?oi=bibs\&cluster $=947193$ 741435004997\&btnI=1\&hl=en \&authuser=1

[25] Umama Yezdani, Mahmood Ali, Mohammad Gayoor Khan,Ayush Kumar, Prince Bhalla and Mayur Sadar, Pharma- cological and NonPharmacological approaches to Vitiligo, World journal of pharmaceutical research•2019; 8(9):884-892.

Citation: Ayush Kumar, et al. The Brief Study on AHF at Government Hospital Madhya Pradesh Chhatarpur District; Treatment Outcomes among Patient, ARC Journal of Cardiology. 2020; 6(1): 1-5. doi:dx.doi.org/ 10.20431/2455-5991.0601001.

Copyright: (C) 2020 Authors. This is an open-access article distributed under the terms of the Creative Commons Attribution License, which permits unrestricted use, distribution, and reproduction in any medium, provided the original author and source are credited. 